D) Check for updates

Cite this: Org. Biomol. Chem., 2019, 17, 6905

\section{Stereoselective deconjugation of macrocyclic $\alpha, \beta$-unsaturated esters by sequential amidation and olefin transposition: application to enantioselective phase-transfer catalysis $\uparrow+$}

\author{
Alexandre Homberg, (DD a Radim Hrdina, (D) a Mahesh Vishe, (iD a Laure Guénée (iD b \\ and Jérôme Lacour (iD *a
}

\begin{abstract}
The stereoselective synthesis of chiral macrocycles bearing two aliphatic amide functional groups is reported. After the amidation mediated by TBD, a guanidine derivative, the olefin transposition step is performed with a slight excess of $t$-BuOK. The products are afforded in moderate to good combined yields (up to 59\%) and with an excellent syn diastereoselectivity ( $d r>49: 1)$. Introducing enantiopure $\alpha$-branched substituents was possible and it resulted in mixtures of diastereomers, which could be tested as phase-transfer catalysts using the formation of a phenylalanine analog as a test reaction (up to $43 \%$ ee). A clear matched-mismatched situation was observed in the two diastereomeric series.
\end{abstract}

Received 14th June 2019, Accepted 26th June 2019 DOI: $10.1039 /$ c9ob01355e rsc.li/obc been used as pH-independent nanosensors, ${ }^{5}$ heteroditopic receptors for salts, ${ }^{6}$ ratiometric luminescent or reversible chiroptical switches ${ }^{7}$ and circularly-polarized electrochemiluminescent emitters. ${ }^{8}$ Herein, the stereoselective synthesis of macrocycles of type 3 bearing two aliphatic amide functional groups is reported (Scheme 1B, right). A two-step process is

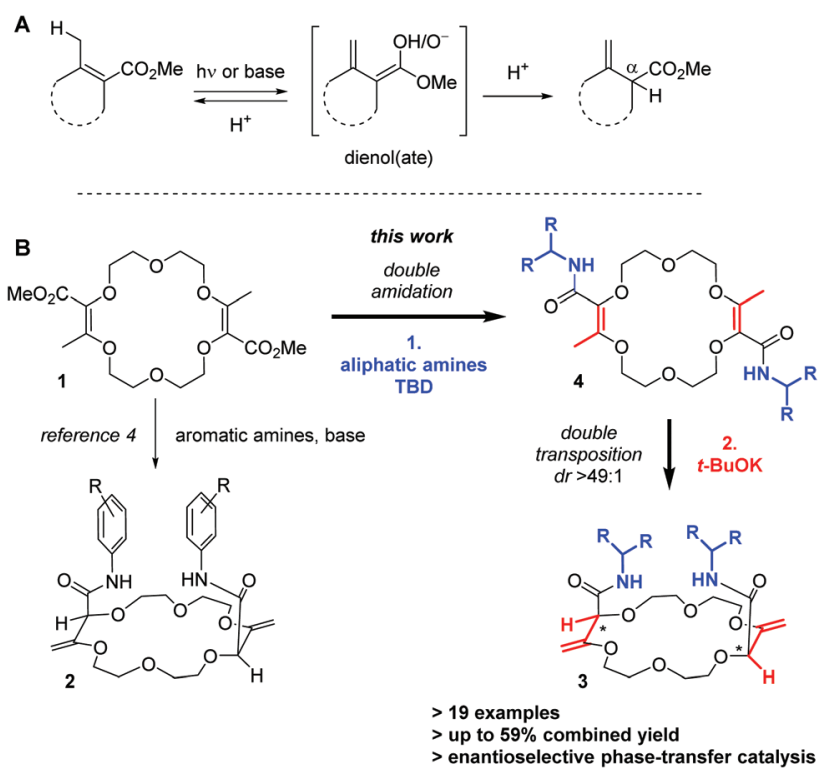

Scheme 1 Typical conditions for the deconjugation of $\alpha, \beta$-unsaturated esters (A). Remote stereoselective synthesis of chiral polyether macrocycles (B, syn transposition, $d r>49: 1$ ).

\footnotetext{
${ }^{a}$ Department of Organic Chemistry, University of Geneva, Quai Ernest Ansermet 30, 1211 Geneva 4, Switzerland.E-mail: jerome.lacour@unige.ch

${ }^{b}$ Laboratory of Crystallography, University of Geneva, Quai Ernest Ansermet 24, 1211 Geneva 4, Switzerland

$\uparrow$ The dataset for this article can be found at the following DOI: $10.26037 /$ yareta: fp326563trgt3gp3l3ofsyfiem. It will be preserved for 10 years.

$\$$ Electronic supplementary information (ESI) available: Experimental conditions, full characterization, ${ }^{1} \mathrm{H}$ NMR, ${ }^{13} \mathrm{C}$ NMR and ${ }^{19} \mathrm{~F}$ NMR spectra of all new compounds (PDF), and CSP-HPLC traces. CCDC 1923025-1923027. For ESI and crystallographic data in CIF or other electronic format see DOI: 10.1039/ c9ob01355e
} 
this time necessary. Amine additions are mediated by TBD (1,5,7-triazabicyclo[4.4.0]dec-5-ene), a guanidine derivative that helps in the formation of the $\alpha, \beta$-unsaturated amide derivatives 4 . Then, olefin transpositions under basic conditions ( $t$-BuOK) afford the corresponding chiral macrocycles 3 with high syn diastereoselectivity ( $d r>49: 1$, yields up to $59 \%$ for the combined steps). Chiral enantiopure amines can be utilized and after the preparation of the resulting diastereomers, macrocycles were used as phase-transfer catalysts. In the enantioselective alkylation of a protected glycine (ee up to $43 \%$ ), a clear matched-mismatched situation is observed in the two diastereomeric series.

\section{Results and discussion}

\section{Initial attempts}

Previously, it was shown that methyl $\alpha$-diazo- $\beta$-ketoester reacts with 1,4-dioxane under dirhodium catalysis in a formal $[3+6+$ $3+6$ ] multi-component condensation. The process is mild and affords the resulting unsaturated macrocycle 1 on a multigram scale (up to 20 grams) while using a low catalyst loading (0.01-0.001 mol\%). ${ }^{9,10}$ As mentioned earlier, compound 1 reacts with excesses of $\mathrm{ArNH}_{2}$ and $t$-BuOK (>3 equiv. each) to yield unsaturated bis(aromatic) derivatives 2 . This reaction tolerates a large variety of aromatic amines. ${ }^{4-8,11}$ However, despite major efforts by the group, it was never possible to achieve the analogous $\mathbf{1} \rightarrow \mathbf{3}$ transformation with aliphatic amines instead of anilines. Of the two consecutive steps, it was clearly the first one that was problematic under the previous conditions. Care was thus taken to decouple the two steps of the process and perform the amide formation first, prior to the olefin transposition.

\section{Optimization of the two-step process}

For the transformation of macrocycle 1 into the corresponding $\alpha, \beta$-unsaturated bis(aliphatic) macrocycles 4 , mild conditions of amidation were looked for. With regular non-activated esters, ${ }^{12}$ the use of additives such as (Lewis) acids, ${ }^{13}$ bases, ${ }^{14}$ metal salts and complexes, ${ }^{15}$ enzymes ${ }^{16}$ or organocatalysts is required to promote the reaction. ${ }^{17}$ Many such conditions were tested using macrocycle $\mathbf{1}$ and benzyl amine as the model substrate and reagent, respectively (Table 1). Heating the macrocycle and the amine in THF at $60{ }^{\circ} \mathrm{C}$ did not induce a conversion (entry 1). Strongly basic conditions, $t$-BuOK or $n$-BuLi, led either to a total degradation or a partial $30 \%$ conversion of macrocycle 1 respectively (entries 2 and 3). Lewis acids $\left(\mathrm{Yb}(\mathrm{OTf})_{3}, \mathrm{BF}_{3} \cdot \mathrm{OEt}_{2}\right)$ and $\mathrm{N}$-heterocyclic carbenes were also tested (entries 4-10). In many instances, a lack of reactivity was observed. Otherwise, it was a full degradation of $\mathbf{1}$. Previously, for the transformation of esters into amides, Mioskowski and collaborators used TBD as the catalyst. ${ }^{17 g, 18,19,20}$ Using $20 \mathrm{~mol} \%$ of this cyclic guanidine base, an amidation could not be observed (entry 11). ${ }^{21}$ However, with a stoichiometric amount of it (2 equiv.), macrocycle $4 \mathbf{a}$ was obtained in a satisfactory yield $(47 \%)$ after 4 hours of reaction and a simple filtration (entry 12). Increasing the reaction
Table 1 Amidation of 1: optimization

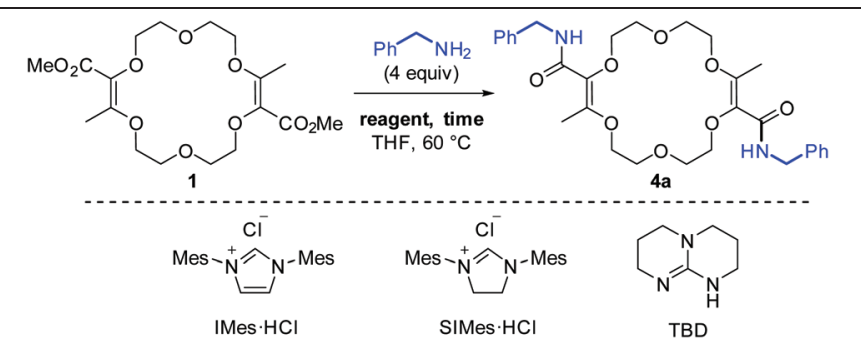

\begin{tabular}{|c|c|c|c|}
\hline Entry & Reagent (equiv.) & Time (h) & Isolated yield \\
\hline 1 & - & 15 & No conv. \\
\hline $2^{a}$ & $t$-BuOK (4) & 3 & Degradation \\
\hline $3^{a}$ & $n$-BuLi (4) & 3 & $<30 \%$ conv. $^{b}$ \\
\hline 4 & $\mathrm{Yb}(\mathrm{OTf})_{3}(0.1)$ & 15 & No conv. \\
\hline 5 & $\mathrm{Yb}(\mathrm{OTf})_{3}(2)$ & 15 & No conv. \\
\hline 6 & $\mathrm{BF}_{3} \cdot \mathrm{OEt}_{2}(0.2)$ & 15 & No conv. \\
\hline 7 & $\mathrm{BF}_{3} \cdot \mathrm{OEt}_{2}(2)$ & 15 & No conv. \\
\hline 8 & $\mathrm{IMes} \cdot \mathrm{HCl} / t-\mathrm{BuOK}(0.05)$ & 15 & No conv. \\
\hline 9 & IMes·HCl/t-BuOK (2) & 15 & Degradation \\
\hline 10 & $\mathrm{SIMes} \cdot \mathrm{HCl} / t$-BuOK (2) & 15 & Degradation \\
\hline 11 & $\operatorname{TBD}(0.2)$ & 15 & No conv. \\
\hline 12 & TBD (2) & 4 & $47 \%$ \\
\hline 13 & TBD (2) & 15 & $75 \%$ \\
\hline
\end{tabular}

${ }^{a}-100{ }^{\circ} \mathrm{C}(1 \mathrm{~min})$, then $25{ }^{\circ} \mathrm{C}$ instead of $60{ }^{\circ} \mathrm{C} .{ }^{b}$ The isolation of $4 \mathrm{a}$ was attempted but failed; abbreviations: Mes = mesityl.

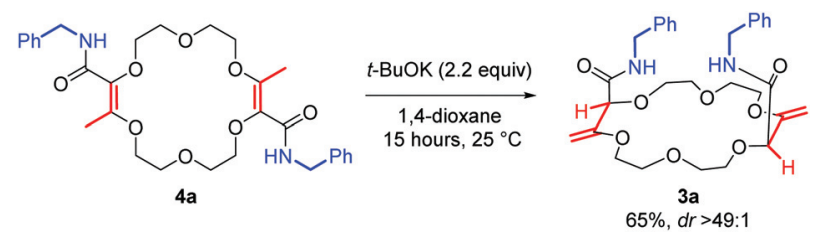

Scheme 2 Base-induced olefin transposition of $4 a$ to form $3 a$.

time to 15 hours afforded $\mathbf{4 a}$ in $75 \%$ yield (entry 10 ). The structure of $4 \mathbf{a}$ was confirmed by NMR spectroscopy and X-ray diffraction analysis (see Fig. 1A).

Next, the olefin transposition of compound 4a was considered under basic conditions. ${ }^{4}$ After optimization
A

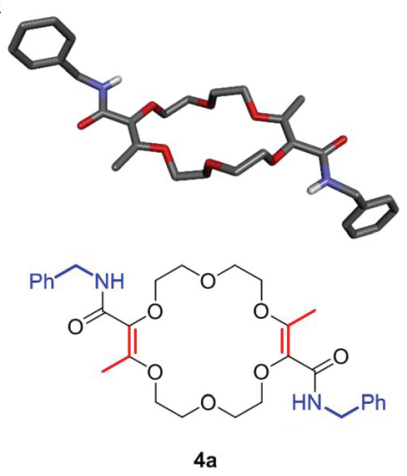

B

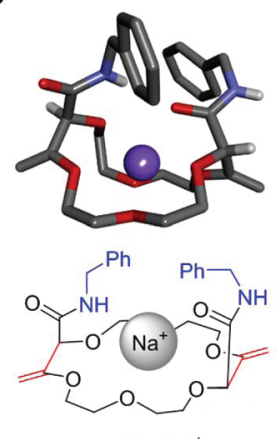

$[\mathrm{Na} \cdot 3 \mathrm{a}]^{+}$
Fig. 1 Stick view of the crystal structure of $4 a(A)$ and $[\mathrm{Na} \cdot 3 a]\left[B A r_{F}\right](B)$ $\left(\mathrm{BAr}_{\mathrm{F}}\right.$ anion and most hydrogen atoms are hidden for clarity). 
(Table S1 ${ }^{\dagger}$ ), it was found that the combination of $t$-BuOK (2.2 equiv.) and 1,4-dioxane as the solvent afforded the best conditions. ${ }^{22}$ Macrocycle 3a was isolated in good yield (65\%, Scheme 2) as a single diastereoisomer $\left(d r>49: 1,{ }^{1} \mathrm{H}\right.$ NMR monitoring). Once again, an effective remote stereoselectivity is noticed in this type of process. ${ }^{4}$ The relative configuration of 3a was determined by the solid state structure of the sodium BAr $_{\mathrm{F}}$ (tetrakis[3,5-bis(trifluoromethyl)phenyl]borate) adduct (Fig. 1B). Only the chiral cis-diastereoisomer (racemic) is formed during the reaction and traces of the achiral (meso, trans) stereoisomer could not be detected. This result indicates that the mechanism for the olefin transposition(s) is similar to that previously reported $;{ }^{4}$ the potassium ion acts as a template and helps to relay the second reprotonation on the same prochiral face as the first one.

In solution, compounds 3 differ from the bis-anilide derivatives 2 . In fact, in terms of the simple host-guest chemistry, it had been previously observed that a water molecule is usually complexed inside the cavity of macrocycles $2 .^{4}$ Herein, in chloroform- $d$, there is little of interaction of $\mathbf{3 a}$ with water as monitored by ${ }^{1} \mathrm{H}$ NMR spectroscopy at different concentrations (8-116 mM, see the ESI\$). In comparison with the aniline series (compounds 2), the proton signals of the amide groups or of the water molecule are only weakly perturbed.

\section{2-Step process: scope and (lack of) asymmetric induction with enantiopure amines}

With the optimal conditions for the amidation and the olefin transposition in hand, various linear and $\alpha$-branched amines were introduced. In Table 2, the yields are reported for the two steps. In general, with linear primary amines, moderate to good combined yields were obtained $(35-55 \%)$; the nature of the side chains has little influence on the outcome. For the standard reaction, macrocycle 3 a was obtained in $54 \%$ overall yield. Methyl, propyl, octyl and allyl substituted derivatives $\mathbf{3 b}$ to $3 \mathrm{e}$ were obtained in similar yields $(42 \%-55 \%)$. Silyl or methyl protected amino alcohols were used and afforded macrocycles $3 \mathbf{f}$ to $3 \mathbf{h}$ in $35 \%$ to $54 \%$ yield. $^{23}$

However, when the introduction of $\alpha$-branched amines was investigated under the above conditions, only poor conversions were observed for the first amidation step, the sterically-hindered amines being much less reactive. It was necessary to increase both the amount of TBD (from 2 to 4 equiv.) and the reaction time (15 hours to 10 days) to reach full conversion of 1. Then, upon transposition with $t$-BuOK, macrocycles $3 \mathbf{i}$ $(i$-Pr) and $3 \mathbf{j}$ ( $c$-Hex) were obtained in moderate combined yields (29\% and 18\%, respectively). Similarly, with enantiopure $\alpha$-alkyl substituted benzyl or methylnaphthyl amines, we could isolate the corresponding macrocycles $3 \mathbf{k}$ to $3 \mathbf{s}$ (15-35\%). In all these reactions, the critical step in terms of yield is not the transposition but the amidation. In fact, a slow competitive degradation of the starting macrocycle 1 occurs during the amidation that disfavors the overall process. ${ }^{24}$

Finally, care was taken to study the stereochemical outcome of the reaction in the presence of enantiopure $\alpha$-branched amines. $^{25}$ Satisfactorily, the double transposition still occurs
Table 2 Combined yields (two steps) of macrocycles 3a-3s

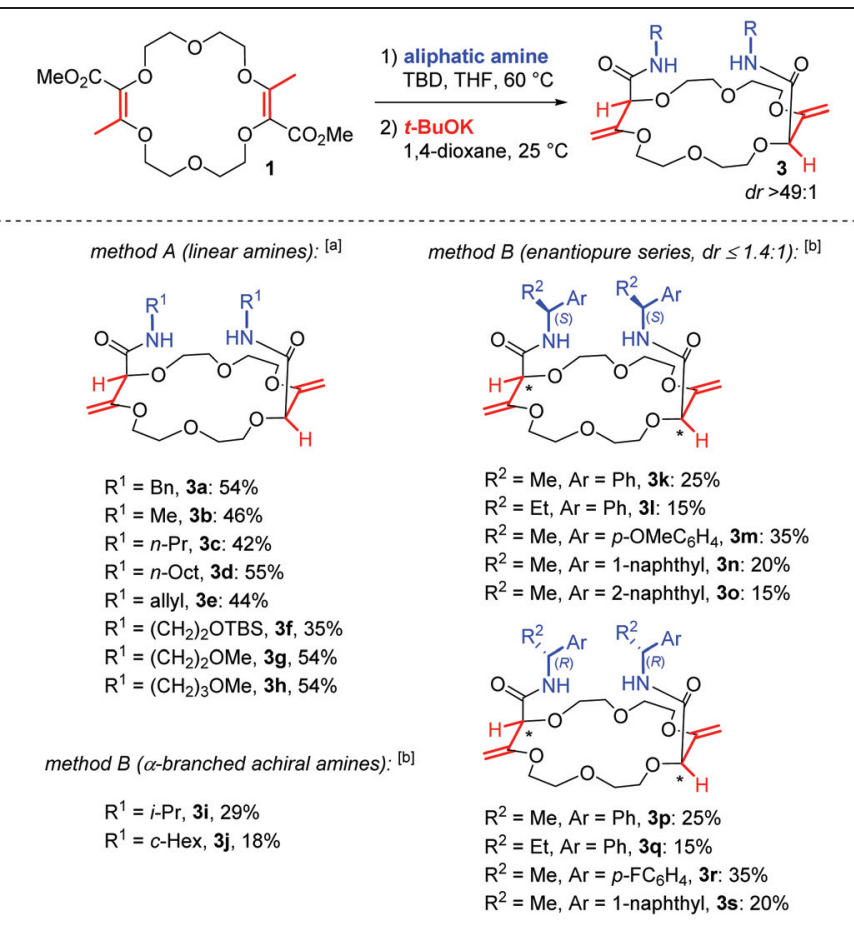

${ }^{a}$ Method A: 1 ( $\left.0.25 \mathrm{mmol}\right)$, linear amine (4.0 equiv.), TBD (2.0 equiv.), THF, $60{ }^{\circ} \mathrm{C}, 15$ hours; then $t$-BuOK $\left(2.2\right.$ equiv.), dioxane, $25{ }^{\circ} \mathrm{C}$, 15 hours. ${ }^{b}$ Method B: 1 ( $\left.0.25 \mathrm{mmol}\right), \alpha$-branched amine (4.0 equiv.), TBD (4.0 equiv.), THF, $60{ }^{\circ} \mathrm{C}, 10$ days; then $t$-BuOK (2.2 equiv.), dioxane, $25{ }^{\circ} \mathrm{C}, 15$ hours. Macrocycles $3 \mathbf{k}$ to $3 \mathbf{s}$ are obtained as mixtures of diastereoisomers $(1: 1 \leq d r \leq 1.4: 1$, see the ESI).

with a syn stereoselectivity but it leads, this time, to two different products. Indeed, the enantiopure amine residues exert little influence on the newly created stereogenic centers inside the macrocyclic skeleton and two diastereoisomers are formed. For instance, with $(S)$-phenylethylamine, product $\mathbf{3 k}$ exists in two different $(S, S, S, S)$ and $(S, R, R, S)$ configurations with a low overall stereoselectivity $(d r 1.3: 1) .{ }^{26}$ Several other amines were tested and the selectivity has remained low in all cases $(d r \leq 1.4: 1)$. In Table 2 , the yields are given for the two steps and both diastereoisomers together; the stereoisomers were separated in only one instance (see the next paragraph).

\section{Application: enantioselective phase-transfer catalysis}

Crown ethers, thanks to their ability to complex alkali metal salts and render them soluble in both polar and apolar solutions, are efficient phase-transfer catalysts (PTCs). Several chiral non-racemic versions of these derivatives have been developed and applied in various enantioselective reactions such as alkylations, 1,4-additions or oxidations. ${ }^{27}$ It was then logical to test compounds $3 \mathbf{k}$ to $3 \mathbf{s}$ bearing $\alpha$-branched enantiopure substituents as PTCs. We selected the alkylation of protected glycine $\mathbf{5}$ with benzyl bromide which affords chiral phenylalanine derivative $\mathbf{6}$ as the product as the benchmark; this reaction occurs only in the presence of catalysts (Table 3, entry 1). ${ }^{28}$ The different macrocycles were reacted under con- 
Table 3 Asymmetric phase-transfer catalysis with $3 n^{a}$

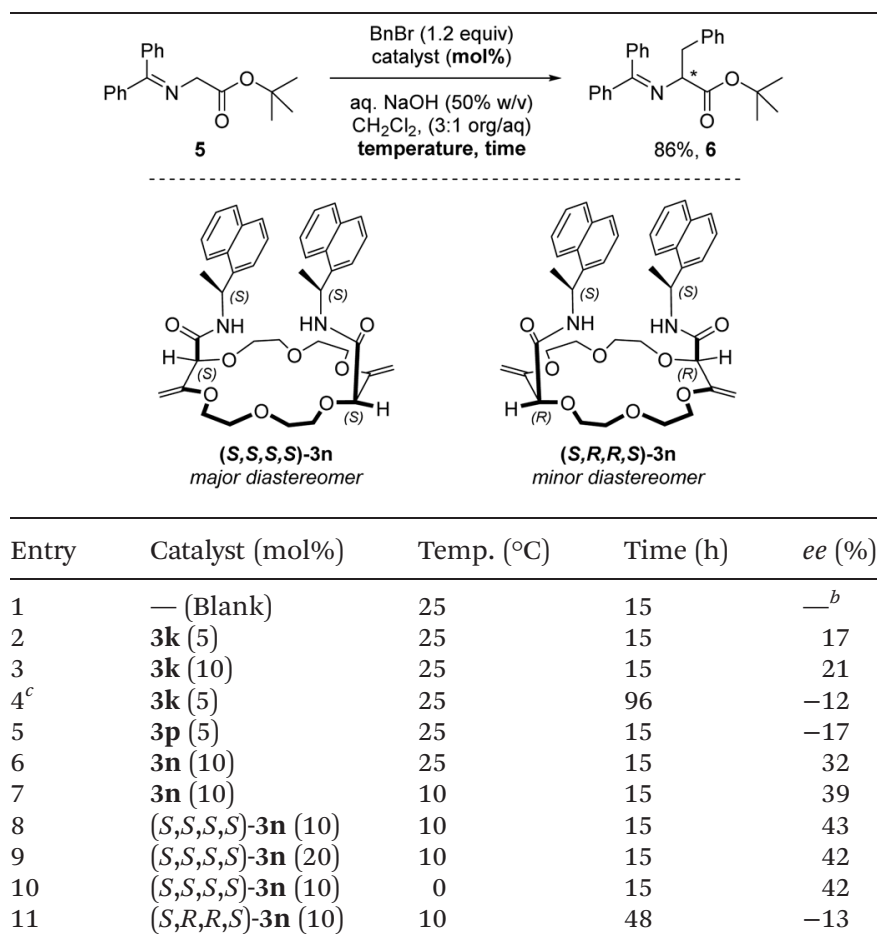

${ }^{a}$ For all catalyzed reactions, isolated yields are consistent in the range of $85-87 \%$. ${ }^{b}$ No conversion of $5 .{ }^{c}$ In toluene instead of $\mathrm{CH}_{2} \mathrm{Cl}_{2}$.

ditions that are standard for phase-transfer catalysis with chiral crown ethers (Tables S2-S5 $\$$ ). Overall and not surprisingly, it was found that sodium and potassium salts afforded the best conversions (Table $\mathrm{S} 3 \ddagger$ ). A rather large screening of solvents was also performed and $\mathrm{CH}_{2} \mathrm{Cl}_{2}$ was the most favorable followed by 1,1-dichloroethane and 1,1,1-trichloroethane, similar ee values however being observed (Table S5 $\$$ ). With derivative $3 \mathbf{k}$ as the catalyst ( $5 \mathrm{~mol} \%$, Table 3 , entry 2 ), amino acid (+)-6 was obtained in good yield (86\%) and low enantioselectivity $(17 \%$ ee $)$. The increase of catalyst loading to $10 \mathrm{~mol} \%$ improved slightly the enantiomeric excess to $21 \%$ (entry 3). With toluene as the solvent, a longer reaction time, lower enantioselectivity and reversal of the stereoinduction in favor of the antipodal enantiomer (-)-6 were observed (entry 4). Using macrocycle $3 \mathbf{p}$ (with an inverted configuration on the amide side chain), analogous results to $3 \mathbf{k}$ were obtained in favor of the levorotatory enantiomer. It was then shown that 1-naphthyl derivative $\mathbf{3 n}$ is the most efficient in the series (see the ESI ). Using $3 n$ as the PTC (10 mol\%, $d r$ 1.4:1) at $25{ }^{\circ} \mathrm{C}$, amino acid (+)-6 was obtained in good yield (86\%) and moderate enantioselectivity ( $32 \% e e$ ) (Table 3 , entry 6). Decreasing the temperature to $10{ }^{\circ} \mathrm{C}$ improved slightly the enantiomeric excess (39\% ee, entry 7). The two diastereoisomers of $\mathbf{3 n}$, namely $(S, S, S, S)-\mathbf{3 n}$ (major) and $(S, R, R, S)-\mathbf{3 n}$ (minor), could be separated by column chromatography $\left(\mathrm{SiO}_{2}\right.$, $\mathrm{CH}_{2} \mathrm{Cl}_{2} / \mathrm{MeOH}$ gradient) and used independently in the phasetransfer reaction. The configuration of $(S, S, S, S)-3 \mathbf{n}$ was ascertained by the X-ray structural analysis of the $\operatorname{NaBAr}_{\mathrm{F}}$ salt.
With $(S, S, S, S)$-3n, the dextrorotatory enantiomer of $\mathbf{6}$ was again favored with a slightly improved enantiomeric excess (43\% ee, entry 8). Higher catalyst loading (20 mol\%) or temperature decrease $\left(0{ }^{\circ} \mathrm{C}\right)$ did not lead to a larger enantioinduction (entries 9 and 10). Interestingly, using the minor diastereoisomer $(S, R, R, S)$-3n and after a longer reaction time (48 hours), the antipodal enantiomer (-)-6 was obtained in $86 \%$ yield and only a $13 \%$ ee value (entry 11 ). The difference in reactivity and selectivity between the two diastereoisomers of $\mathbf{3 n}$ illustrates thus a clear matched-mismatched situation in the enantioselective alkylation of glycine 5 .

\section{Conclusion}

Starting from the readily prepared unsaturated macrocyclic precursor 1, chiral crown ethers bearing two aliphatic amide functional groups were synthesized. It was necessary to separate the amidation (mediated by TBD) and the olefin transposition step (induced by a slight excess of $t$-BuOK). The products were afforded in moderate to good combined yields (up to 59\%) and with an excellent syn diastereoselectivity $(d r>49: 1)$. Introducing enantiopure $\alpha$-branched substituents was possible and resulted in mixtures of diastereomers, which could be tested as phase-transfer catalysts using the formation of enantioenriched phenylalanine analogs as a benchmark (up to $43 \% e e$ ). In this reaction, a clear matched-mismatched situation was observed in the two diastereomeric series.

\section{Conflicts of interest}

There are no conflicts to declare.

\section{Acknowledgements}

We thank the University of Geneva and the Swiss National Science Foundation for financial support (SNF 200020-172497 and 200020-184843). We acknowledge the contributions of the Sciences Mass Spectrometry (SMS) platform at the Faculty of Sciences, University of Geneva. We thank Professor Dr Klaus Ditrich (BASF) for generous gifts of the chiral enantiopure amines.

\section{Notes and references}

1 (a) F. Bargiggia and O. Piva, Tetrahedron: Asymmetry, 2003, 14, 1819-1827; (b) T. Bach and F. Höfer, J. Org. Chem., 2001, 66, 3427-3434; (c) O. Piva, J. Org. Chem., 1995, 60, 7879-7883; (d) O. Piva and J.-P. Pete, Tetrahedron: Asymmetry, 1992, 3, 759-768; (e) R. Mortezaei, D. Awandi, F. Henin, J. Muzart and J. P. Pete, J. Am. Chem. Soc., 1988, 110, 4824-4826; (f) S. L. Eng, R. Ricard, C. S. K. Wan and A. C. Weedon, J. Chem. Soc., Chem. Commun., 1983, 236238; $(g)$ J. R. Scheffer and B. A. Boire, J. Am. Chem. Soc., 
1971, 93, 5490-5495; (h) M. J. Jorgenson, J. Am. Chem. Soc., 1969, 91, 198-200; (i) G. Buechi and S. H. Feairheller, J. Org. Chem., 1969, 34, 609-612; (j) R. R. Rando and W. V. E. Doering, J. Org. Chem., 1968, 33, 1671-1673; (k) M. J. Jorgenson and T. Leung, J. Am. Chem. Soc., 1968, 90, 3769-3774; (l) M. J. Jorgenson and N. C. Yang, J. Am. Chem. Soc., 1963, 85, 1698-1699.

2 (a) J. Martin, J.-C. Plaquevent, J. Maddaluno, J. Rouden and M.-C. Lasne, Eur. J. Org. Chem., 2009, 5414-5422; (b) E. Vedejs, A. W. Kruger, N. Lee, S. T. Sakata, M. Stec and E. Suna, J. Am. Chem. Soc., 2000, 122, 4602-4607; (c) C. Fehr, Angew. Chem., Int. Ed. Engl., 1996, 35, 25662587; (d) A. C. Weedon, Can. J. Chem., 1984, 62, 1933-1939.

3 (a) C. Fehr, N. Chaptal-Gradoz and J. Galindo, Chem. - Eur. J., 2002, 8, 853-858; (b) C. Fehr and J. Galindo, Angew. Chem., Int. Ed. Engl., 1994, 33, 1888-1889; (c) C. Fehr, I. Stempf and J. Galindo, Angew. Chem., Int. Ed. Engl., 1993, 32, 1042-1044; (d) C. Fehr, I. Stempf and J. Galindo, Angew. Chem., Int. Ed. Engl., 1993, 32, 1044-1046; (e) C. Fehr and J. Galindo, J. Am. Chem. Soc., 1988, 110, 6909-6911.

4 M. Vishe, R. Hrdina, A. I. Poblador-Bahamonde, C. Besnard, L. Guénée, T. Bürgi and J. Lacour, Chem. Sci., 2015, 6, 4923-4928.

5 Z. Jarolímová, M. Vishe, J. Lacour and E. Bakker, Chem. Sci., 2016, 7, 525-533.

6 S. K. Ray, A. Homberg, M. Vishe, C. Besnard and J. Lacour, Chem. - Eur. J., 2018, 24, 2944-2951.

7 (a) A. Homberg, E. Brun, F. Zinna, S. Pascal, M. Górecki, L. Monnier, C. Besnard, G. Pescitelli, L. Di Bari and J. Lacour, Chem. Sci., 2018, 9, 7043-7052; (b) S. Sinn, F. Biedermann, M. Vishe, A. Aliprandi, C. Besnard, J. Lacour and L. De Cola, ChemPhysChem, 2016, 17, 18291834.

8 F. Zinna, S. Voci, L. Arrico, E. Brun, A. Homberg, L. Bouffier, T. Funaioli, J. Lacour, N. Sojic and L. Di Bari, Angew. Chem., Int. Ed., 2019, 58, 6952-6956.

9 (a) D. Poggiali, A. Homberg, T. Lathion, C. Piguet and J. Lacour, ACS Catal., 2016, 6, 4877-4881; (b) M. Vishe, R. Hrdina, L. Guénée, C. Besnard and J. Lacour, Adv. Synth. Catal., 2013, 355, 3161-3169; (c) W. Zeghida, C. Besnard and J. Lacour, Angew. Chem., Int. Ed., 2010, 49, 7253-7256.

10 Macrocycles of different scaffolds or sizes can be obtained using similar Rh(II)-catalyzed procedures by condensation of $\alpha$-diazo- $\beta$-ketoesters with other small cyclic ethers such as THP, THF, oxetane, oxepane or morpholines. See ref. 9.

11 M. Vishe, T. Lathion, S. Pascal, O. Yushchenko, A. Homberg, E. Brun, E. Vauthey, C. Piguet and J. Lacour, Helv. Chim. Acta, 2018, 101, e1700265.

12 For examples of amidation without the help of external reagents or catalysts, see: (a) S. Furukawa, T. Fukuyama, A. Matsui, M. Kuratsu, R. Nakaya, T. Ineyama, H. Ueda and I. Ryu, Chem. - Eur. J., 2015, 21, 11980-11983; (b) N. D. Karis, W. A. Loughlin and I. D. Jenkins, Tetrahedron, 2007, 63, 12303-12309; (c) F.-Z. Zradni, J. Hamelin and A. Derdour, Synth. Commun., 2002, 32, 3525-3531.
13 (a) A. Mondal, M. Subaramanian, A. Nandakumar and E. Balaraman, Org. Lett., 2018, 20, 3381-3384; (b) D. T. Nguyen, D. C. Lenstra and J. Mecinovic, RSC Adv., 2015, 5, 77658-77661; (c) H. Morimoto, R. Fujiwara, Y. Shimizu, K. Morisaki and T. Ohshima, Org. Lett., 2014, 16, 2018-2021; (d) C. L. Allen and J. M. J. Williams, Chem. Soc. Rev., 2011, 40, 3405-3415; (e) V. M. de Oliveira, R. Silva de Jesus, A. F. Gomes, F. C. Gozzo, A. P. Umpierre, P. A. Z. Suarez, J. C. Rubim and B. A. D. Neto, ChemCatChem, 2011, 3, 1911-1920; (f) A. Novak, L. D. Humphreys, M. D. Walker and S. Woodward, Tetrahedron Lett., 2006, 47, 5767-5769; $(g)$ R. Arora, S. Paul and R. Gupta, Can. J. Chem., 2005, 83, 1137-1140; (h) C. Han, J. P. Lee, E. Lobkovsky and J. A. Porco, J. Am. Chem. Soc., 2005, 127, 10039-10044; (i) B. C. Ranu and P. Dutta, Synth. Commun., 2003, 33, 297-301; (j) K. Ishihara, Y. Kuroki, N. Hanaki, S. Ohara and H. Yamamoto, J. Am. Chem. Soc., 1996, 118, 1569-1570.

14 (a) N. Caldwell, C. Jamieson, I. Simpson and A. J. B. Watson, Chem. Commun., 2015, 51, 9495-9498; (b) N. Caldwell, P. S. Campbell, C. Jamieson, F. Potjewyd, I. Simpson and A. J. B. Watson, J. Org. Chem., 2014, 79, 9347-9354; (c) N. Caldwell, C. Jamieson, I. Simpson and A. J. B. Watson, ACS Sustainable Chem. Eng., 2013, 1, 13391344; (d) T. Ohshima, Y. Hayashi, K. Agura, Y. Fujii, A. Yoshiyama and K. Mashima, Chem. Commun., 2012, 48, 5434-5436; (e) V. R. Chintareddy, H.-A. Ho, A. D. Sadow and J. G. Verkade, Tetrahedron Lett., 2011, 52, 6523-6529; (f) S. A. Rzhevskiy, A. A. Ageshina, G. A. Chesnokov, P. S. Gribanov, M. A. Topchiy, M. S. Nechaev and A. F. Asachenko, RSC Adv., 2019, 9, 1536-1540.

15 (a) Y.-L. Zheng and S. G. Newman, ACS Catal., 2019, 9, 4426-4433; (b) B. Gnanaprakasam and D. Milstein, J. Am. Chem. Soc., 2011, 133, 1682-1685.

16 (a) K. P. Dhake, Z. S. Qureshi, R. S. Singhal and B. M. Bhanage, Tetrahedron Lett., 2009, 50, 2811-2814; (b) L. Couturier, D. Taupin and F. Yvergnaux, J. Mol. Catal. B: Enzym., 2009, 56, 29-33; (c) N. Aoyagi, S. Kawauchi and T. Izumi, Tetrahedron Lett., 2003, 44, 5609-5612.

17 (a) J. Lauberteaux, D. Pichon, O. Baslé, M. Mauduit, R. M. de Figueiredo and J.-M. Campagne, ChemCatChem, 2019, 11, 1-19; (b) L.-Y. Chen and M.-F. Wu, Synthesis, 2019, 1595-1602; (c) H. Guo, Y. Wang, G.-F. Du, B. Dai and L. He, Tetrahedron, 2015, 71, 3472-3477; (d) F. J. Weiberth, Y. Yu, W. Subotkowski and C. Pemberton, Org. Process Res. Dev., 2012, 16, 1967-1969; (e) X. Yang and V. B. Birman, Org. Lett., 2009, 11, 1499-1502; (f) K. E. Price, C. LarrivéeAboussafy, B. M. Lillie, R. W. McLaughlin, J. Mustakis, K. W. Hettenbach, J. M. Hawkins and R. Vaidyanathan, Org. Lett., 2009, 11, 2003-2006; (g) C. Sabot, K. A. Kumar, S. Meunier and C. Mioskowski, Tetrahedron Lett., 2007, 48, 3863-3866; (h) M. Movassaghi and M. A. Schmidt, Org. Lett., 2005, 7, 2453-2456; (i) S. Karthik, K. Muthuvel and T. Gandhi, J. Org. Chem., 2019, 84, 738-751.

18 TBD is usually used as an organocatalyst for transesterification or ester polymerization reactions. See: (a) R. Yuan, 
Q. Shou, Q. Mahmood, G. Xu, X. Sun, J. Wan and Q. Wang, Synlett, 2019, 928-931; (b) S. Park and J. G. Kim, Beilstein J. Org. Chem., 2019, 15, 963-970; (c) M. K. Kiesewetter, M. D. Scholten, N. Kirn, R. L. Weber, J. L. Hedrick and R. M. Waymouth, J. Org. Chem., 2009, 74, 9490-9496.

19 For the TBD mediated synthesis of carbamate and urea, see: (a) S. Carloni, D. E. De Vos, P. A. Jacobs, R. Maggi, G. Sartori and R. Sartorio, J. Catal., 2002, 205, 199-204; (b) R. Ballini, D. Fiorini, R. Maggi, P. Righi, G. Sartori and R. Sartorio, Green Chem., 2003, 5, 396-398.

20 For the TBD mediated formylation of amines, see: H.-W. Noh, Y. An, S. Lee, J. Jung, S. U. Son and H.-Y. Jang, Adv. Synth. Catal., 2019, 361, 1-7.

21 In addition, increasing the reaction time and/or temperature led only to partial mono addition or to degradation products.

22 The use of 0.2 equivalents of $t$-BuOK led only to a partiallyinduced isomerization (Table S1\$). This indicates that the secondary amide functions are too acidic and it is necess- ary to deprotonate them quantitatively prior to the isomerization.

23 The isomerization does not proceed with unprotected alcohol functional groups. See the ESI.t

24 Full conversion of $\mathbf{1}$ is always reached. The degradation products could unfortunately neither be isolated nor identified.

25 It has been previously shown that TBD does not racemize this type of chiral amine. See ref. $17 \mathrm{~g}$.

26 Both products present a local $C_{2}$-symmetry in solution ( ${ }^{1} \mathrm{H}$ and ${ }^{13} \mathrm{C}$ NMR spectroscopy monitoring).

27 (a) R. Schettini, M. Sicignano, F. De Riccardis, I. Izzo and G. Della Sala, Synthesis, 2018, 4777-4795; (b) Z. Rapi, T. Nemcsok, P. Bagi, G. Keglevich and P. Bakó, Tetrahedron, 2019, DOI: 10.1016/j.tet.2019.06.020.

28 (a) J. Vachon and J. Lacour, Chimia, 2006, 60, 266-275; (b) T. Ooi and K. Maruoka, Angew. Chem., Int. Ed., 2007, 46, 4222-4266; (c) S. Shirakawa and K. Maruoka, Angew. Chem., Int. Ed., 2013, 52, 4312-4348; (d) N. Patel, R. Sood and P. V. Bharatam, Chem. Rev., 2018, 118, 8770-8785. 